\title{
A NOTE ON
}

\section{STICHOCOCCUS BACILLARIS NAEG. AND SOME SPECIES OF CHLORELLA AS MARINE ALGAE}

\author{
By E. A. George \\ Botany School, University of Cambridge
}

(Text-fig. I)

The recent publication (Butcher, I952) of some new marine algal species belonging to genera largely non-marine arouses interest as there are relatively few genera ranging from marine to freshwater habitats. Two of the genera concerned, Chlorella and Stichococcus, are notable for their very wide habitat range in fresh water and on land.

Three marine Stichococcus strains were examined and compared with S. bacillaris Naegeli, 1849 , and with various non-marine strains of that species. The marine strains were (i) Stichococcus cylindricus Butcher, type strain; (ii) another strain identified by Butcher as S. cylindricus; and (iii) Plymouth no. $82=$ Cambridge no. $379 / 5$, also identified by Butcher as $S$. cylindricus. None of these three strains differed appreciably from Naegeli's description of $S$. bacillaris. The shape and dimensions agree, while the presence or absence of a pyrenoid cannot be regarded as decisive. Fritsch (1935) and Smith (I950) say that Stichococcus has no pyrenoid, while Prescott (I95I) states there is one pyrenoid but does not depict it in his illustrations. Forest (1954) is probably nearer the truth when, referring to Ulothrix Kütz. em. Forest (including Ulothrix, Hormidium and Stichococcus), he writes: 'In only one species was the pyrenoid distinctive enough to be of possible critical value'. And that was not a species of Stichococcus Naeg. Though the tendency to fragment is strong in these strains the method of cell division appears typical of the genus and not intermediate between it and Nannochloris as Butcher suggests. The type strain when grown in a sea water and soil biphasic medium produces filaments of usually four to eight cells and occasionally up to I8 cells; while in the other strains seldom are more than two cells seen in a filament.

That Butcher's alga is both aquatic and marine does not warrant its position in a separate species. Though $S$. bacillaris is frequently found in damp terrestrial places it is often also aquatic and like Chlorella is one of the more usual colonists of neglected stock bottles of various solutions and of distilled water. It is not surprising therefore that this alga should be found in estuarine and off-shore marine waters.

To test the impression that $S$. bacillaris is an unexacting plant regarding salinity three strains were grown in (a) Föyn's erdschreiber medium, (b) the 
same but with half-strength sea water, and $(c)$ a similar medium with no sea water added. The strains were, a freshwater strain, Cambridge 379/ I c; a strain isolated from the contents of a cow's rumen, Cambridge 379/re; and the marine Cambridge 379/5. They were grown in the different media for Io days before being inoculated into the cultures for estimation. Haemacytometer counts were made covering the logarithmic phase of growth. Irregularity in

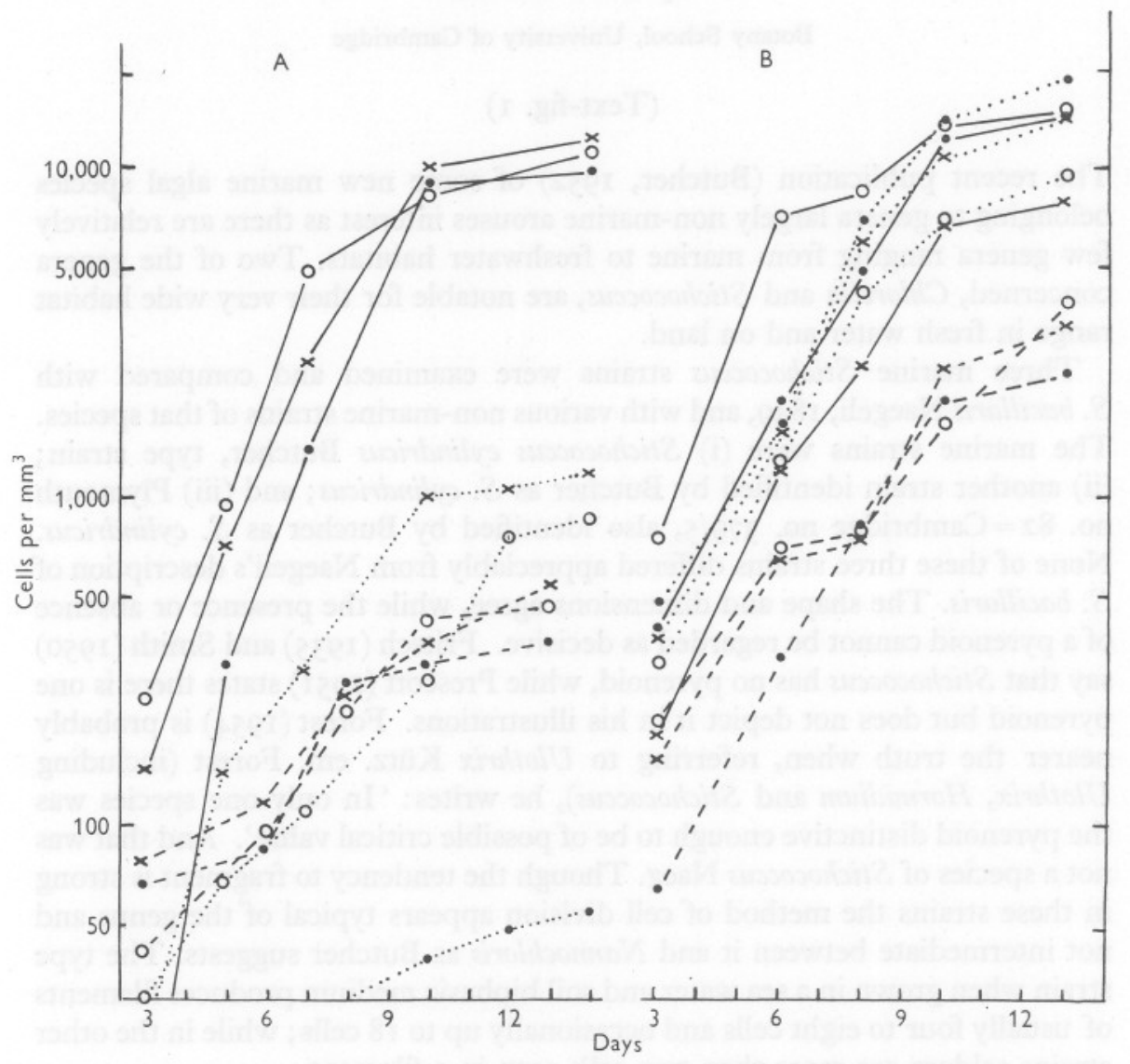

Fig. I. Growth of (A) Stichococcus cultures and (B) Chlorella cultures in (•) sea water, $(x)$ half-strength sea water, and $(O)$ fresh water. A: ...., Stichococcus bacillaris 379/r e; . . ., S. bacillaris $379 / \mathrm{rc} ;-$, S. 'cylindricus' 379/5. B: ..., Chlorella stigmatophora; -...., C. 'Oslo' strain; —, C. ovalis.

some of the counts was due largely to the cells clumping or adhering to the glass despite vigorous shaking. The growth curves (Fig. I A) suggest that the marine form grows equally well in fresh or sea water. The freshwater form is equally tolerant but with lower maximum cell counts. Strain 379/re grew 
perhaps slightly better in half-strength sea water than in fresh water but much more slowly in full-strength sea water.

A similar experiment was done with five Chlorella strains-C. stigmatophora Butcher, Cambridge 2II/20;C. ovalis Butcher, 2II/2I; Chlorella sp. from Oslo Fiord; $C$. vulgaris $2 \mathrm{II} / \mathrm{IIn}$ and $C$. pyrenoidosa $2 \mathrm{II} / 8 \mathrm{c}$; the two latter being freshwater strains. The three marine strains (Fig. I B) show no strong preference for sea water against fresh water. Further investigation would be necessary to ascertain whether there are slight differences of growth due solely to salt concentration. The curves for $C$. vulgaris and $C$. pyrenoidosa showed no measurable growth in sea water and much less growth in half-strength sea water than in freshwater media.

Both these genera are as far as we know completely non-sexual. This implies that every surviving mutation starts a new clonal line and that the microevolution of these forms is entirely a divaricating system. In sexual organisms, on the other hand, there is a frequent recombination of characters within the population, the micro-evolutionary system is reticulate within the breeding group and pure lines are only obtained by artificial methods. Thus the species (or subspecies) in sexual forms is in general the potential breeding group, while in non-sexual forms there will be a large number of clonal lines in the conventional species. These clonal lines will perforce differ slightly from one another either physiologically, or morphologically, or both. In $S$. bacillaris differences of growth rate, tendency to form filaments and tendency to clump irregularly have been noted. To name each of these lines as a separate species would seriously overburden taxonomy, as practically every strain isolated seems slightly different and hence of a different clonal line. All that seems necessary in these forms is an aggregate species, perhaps with subspecies, and the clonal lines, where necessary, known by the reference numbers of a recognized culture collection. Thus it seems best to regard Stichococcus bacillaris as an (aggregate) species including many clonal lines all of which fit Naegeli's description and all of which grow well in fresh or sea water. With the Chlorella strains we have a more difficult problem because the taxonomy of the genus is in need of thorough investigation. However, there are small but constant differences and we may tentatively at least accept Butcher's species while noting that they are very unexacting about salinity.

\section{SUMMARY}

Several strains of Stichococcus bacillaris Naeg. and of the marine S. cylindricus Butcher were all found to fit morphologically in Naegeli's species. Both the marine and non-marine strains grow well in either fresh- or sea-water media. $S$. cylindricus must therefore be regarded as a synonym of $S$. bacillaris. Three marine Chlorella strains including $C$. ovalis Butcher and $C$. stigmatophora Butcher were also found to be quite unexacting about salinity. The significance 
of small differences, particularly of growth rate, is discussed with regard to non-sexual organisms. In general, widely based species are advocated for such organisms, with the clonal lines, where appropriate, designated by the reference number of a recognized culture collection.

\section{REFERENCES}

BUTCHER, R. W., I952. Contributions to our knowledge of the smaller marine algae. F. mar. biol. Ass. U.K., Vol. 31, pp. 175-190.

Forest, H. S., 1954. Discussion of a portion of the Ulotrichaceae. Castanea, Vol. I9, pp. $6 \mathrm{I}-75$.

FrITSCH, F. E., 1935. Structure and Reproduction of the Algae, Vol. I. Cambridge University Press.

NAEgeli, C., I849. Gattungen einzelliger Algen. Zurich.

Prescott, G. W., 1951. Algae of the Western Great Lakes Area. Cranbrook Inst. Sci. SMITH, G. M., 1950. Freshwater Algae of the United States. New York: McGraw Hill. 